\title{
A Hybrid Multiple Criteria Group Decision-Making Approach for Green Supplier Selection in the TFT-LCD Industry
}

\author{
Che-Wei Tsui and Ue-Pyng Wen \\ Department of Industrial Engineering and Engineering Management, National Tsing Hua University, 101 Section 2, \\ Kuang-Fu Road, Hsinchu 30013, Taiwan \\ Correspondence should be addressed to Che-Wei Tsui; d9734804@oz.nthu.edu.tw
}

Received 12 May 2014; Revised 19 July 2014; Accepted 20 July 2014; Published 12 August 2014

Academic Editor: Ren-Jieh Kuo

Copyright ( 2014 C.-W. Tsui and U.-P. Wen. This is an open access article distributed under the Creative Commons Attribution License, which permits unrestricted use, distribution, and reproduction in any medium, provided the original work is properly cited.

\begin{abstract}
The awareness of the need for environmental protection is increasing throughout the world. The focuses of green supplier selection are on considering environmental criteria and strengthening the competitiveness of the entire supply chain. The purpose of this study is to develop a green supplier selection procedure for the thin film transistor liquid crystal display (TFT-LCD) industry using polarizer suppliers as an example. First, a decision framework for green supplier selection is developed based on literatures and the supplier audit forms provided by an anonymous flat panel display manufacturer in Taiwan. Then, a hybrid multiple criteria group decision-making (MCGDM) method is proposed based on analytic hierarchy process (AHP), entropy, elimination and choice expressing the reality III (ELECTRE III), and the linear assignment method to assist the manufacturer in choosing among four polarizer suppliers. The final ranking results for green supplier selection and different opinions from each department are provided. An improvement report is suggested to enhance suppliers' performance. For the evaluation procedure, most managers emphasize the importance of current capability and the capability of research and development. Furthermore, we found that the subsidiary supplier should improve quality control competence immediately to be considered as the potential candidate of primary supplier.
\end{abstract}

\section{Introduction}

With the increasing concern about environmental protection, many enterprises have taken more and more responsibilities for their products to reduce pollution and damage in our environment. Another driver is the environment-protection consciousness from consumers who urge the companies to enhance their ability to make their products greener. Therefore, green supply chain management (GSCM) is considered as a systematic and integrated approach for companies to maintain their sustainability and competitiveness in the market. Among the issues of GSCM, green supplier selection is a crucial issue in improving environmental performance. Therefore, this study focuses on how to develop an effective green supplier selection procedure and facilitate the improvement of the suppliers' performance.

In Taiwan, the optoelectronics industry is the core to promote economic growth, and it is greatly influenced by international regulations, especially those in Europe.
The Photonics Industry and Technology Development Association (PIDA), an organization established by entrepreneurs and academics in Taiwan, reported that the highest output value of the optoelectronics industry was the thin film transistor liquid crystal display (TFT-LCD) industry. The output value of the TFT-LCD industry was approximately US $\$ 35.5$ billion in 2013 , which was approximately $28 \%$ of the global output value [1]. Hung [2] noted that, in addition to the well-known competitors in Japan and Korea, TFTLCD industries in China have emerged due to government support, cheap labor, and an extensive market. Therefore, Taiwanese manufacturers face challenges of making efforts to provide green products that conform to environmental regulations and meet the customers' requests. Consequently, green supplier selection has emerged as an important issue for companies to sustain their market.

Many companies have continually integrated environmental criteria into the supplier audit forms in the past few years, and they have typically used a simple additive 
method to rank the suppliers. However, an effective method is necessary to obtain more information for improving the suppliers' performance. Therefore, the purpose of this study is to develop an effective and systematic evaluation procedure to support the green supplier selection process for the TFT-LCD industry. We attempt to address three research questions. First, we construct a decision framework for green supplier selection suitable for the TFT-LCD industry. Second, we design and propose an effective decision method for ranking and selecting the suppliers for the case-studied TFTLCD panel manufacturer. Finally, we investigate ways to continuously improve suppliers' performance.

In recent years, within the extensive literatures on traditional supplier evaluation and selection [3, 4], issues related to the decision-making tools for green supplier selection have gained increasing interest among researchers [5-9]. Lee et al. [10] divided the green supplier selection model into two stages. The first stage is to differentiate the traditional criteria from the green criteria, and the second stage is to evaluate green suppliers for a high-tech industry using a fuzzy-extended analytic hierarchy process (AHP) method, which is relatively easier. Tuzkaya et al. [11] proposed a hybrid fuzzy multicriteria decision approach, integrating the fuzzy analytic network process (ANP) and a fuzzy outranking method to evaluate suppliers' environmental performance. Kuo et al. [12] integrated artificial neural networks and two multiattribute decision analysis methods (data envelopment analysis and ANP) for green supplier selection. Zhu et al. [13] integrated an ANP method into a green supplier management process model based on portfolio analysis. Büyüközkan [14] applied fuzzy AHP and fuzzy axiomatic design with group decision-making method to select the most appropriate green supplier. Büyüközkan and Çifçi [15] combined a fuzzy decision-making trial and evaluation laboratory (DEMATEL), a fuzzy ANP, and a fuzzy technique for order preference by similarity to an ideal solution (TOPSIS) method to evaluate green suppliers for the case of Ford Otosan Company. Hsu et al. [16] used a hybrid multiple criteria decision-making (MCDM) model to evaluate problems related to recycled materials vendors. The model proposed by $\mathrm{Hsu}$ et al. [16] also considered environmental criteria. The results showed the best vendor and revealed the criteria needed for improvement. Govindan et al. [17] used linguistic scale to determine the experts' subjective weights and applied fuzzy TOPSIS method for suppliers' ranking. Shen et al. [18] proposed fuzzy multiple criteria approach on the basis of the fuzzy TOPSIS method for green supplier evaluation. Yazdani [19] combined fuzzy AHP and fuzzy TOPSIS method for green supplier selection in the automobile manufacturing industry. Chen and Freeman [20] proposed an integrated MCDM approach combining AHP, entropy, and TOPSIS to rank green suppliers. Kannan et al. [21] considered linguistic expression for criteria weights and rank green suppliers using fuzzy TOPSIS method. Zhao and Guo [22] applied fuzzy entropy-TOPSIS approach to select green supplier of thermal power equipment in China.

According to the previous studies, AHP or ANP is usually adopted to obtain the subjective weights of each criterion. The main difference between AHP and ANP is that AHP assumes the independent hierarchies and elements in a decision structure while ANP allows dependence and feedback characteristics among hierarchies and elements. In this study, we will develop a decision framework based on literature review and supplier audit forms of each department. In practice, each department usually designs relevant items on their supplier audit forms and separately evaluates green suppliers' performance. Consequently, the AHP method is more suitable for green supplier selection in the TFT-LCD industry at the current stage. Chen and Freeman [20] applied AHP with entropy weights to determine the compromised weights of criteria for green supplier selection. Based on information theory, the entropy method is a useful method to explore the objective weights determined by a decision maker (DM) and this can avoid overly subjective weights. Therefore, this study considers both subjective weights and objective weights of criteria using the AHP-entropy method. In this study, the combined criteria weights, along with the survey data for empirical analysis, are more suitable for real-world applications.

The issue of green supplier selection is a typical MCDM problem [5]. Few studies have been published about green supplier selection using the MCDM method, especially the outranking method [6]. The main feature of the existing studies is the comparison of all feasible alternatives or actions [23]. The goals of decision-making tools have shifted from finding the right solution to a problem to trying to provide support to the DMs to allow them to advance in the decision process [24]. Therefore, instead of providing a strictly rankbased result, it is even more important to present a result that expresses the DMs' opinion. To accomplish this goal, we adopted the elimination and choice expressing the reality III (ELECTRE III) method, which takes complex information from the traditional and environmental appraisal and ranks the various project options considered. The ELECTRE III method has been shown to be useful when involving many DMs and in the cases where the outcomes of the various alternatives remain uncertain to some degree [25]. It has the characteristics of considering the situations of incomparability and indifference, which causes the ranking result to truly reflect the DMs' opinions. For green supplier selection, many criteria, either qualitative or quantitative, need to be taken into consideration and the ELECTRE III method can also address these criteria simultaneously. Moreover, green supplier selection involves the consideration of multiple feasible alternatives. The ELECTRE III method provides not only the ranking results, but also assistance to suppliers for improvement.

A further point needs to be considered. In real-world applications, green supplier selection is generally a group decision-making process, but most of the previous studies have discussed green supplier selection from the viewpoint of a single DM. A common way to address group decisionmaking problems is to aggregate the weight of the criteria of each DM using the geometric mean [29, 30]. However, few studies have concentrated on aggregating the DMs' evaluation results, while their opinions are important and different in practice. Then, the managers can find a cure for the problem. Thus, green supplier selection is further counted 
as a multiple criteria group decision-making (MCGDM) problem. Bernardo and Blin [31] developed the linear assignment method (LAM) for aggregating a set of ranking results. LAM can aggregate the DMs' ranking results, and it also considers the DMs' weights based on their authority. This study uses LAM to aggregate the different ranking results of each DM based on the results of the ELECTRE III method.

The rest of this paper is organized as follows. Section 2 is the review of recent researches on green supplier selection and the development of a framework for the process of green supplier selection based on the reviewed literatures and supplier audit forms offered by an anonymous TFTLCD manufacturer (the case-studied company in this paper) in Taiwan. Section 3 is the introduction of the proposed method, which combines AHP, the entropy method, ELECTRE III, and LAM. Section 4 is the application of the proposed method to a green supplier selection case and the results. Further discussions and managerial implications are presented in Section 4. In Section 5, concluding remarks are provided.

\section{Green Supplier Selection Criteria}

Due to economic globalization, green procurement can enhance firm competitiveness in GSCM, and green supplier selection has an important role in green procurement. In this section, we will introduce the proposed framework for green supplier selection based on literatures and supplier audit forms from Y-TECH (for confidentiality, a pseudonym is used throughout the study), a well-known TFT-LCD manufacturer in Taiwan and the main case studied in the present research. In this section, we review the published studies and compare them with the supplier audit forms.

According to supplier audit forms from each department, the proposed decision framework can be divided into three aspects: environmental factors (environment, safety, and health $[\mathrm{ESH}]$ department and green product management [GPM] department), enterprise operating (material management $[\mathrm{MM}]$ department and supplier quality management [SQM] department), and strategic technology and development (research and development [RD] department and SQM department). Some published papers have considered the selection issue with only environmental performance [3236]. A few studies have focused on environmental performance for supplier selection $[37,38]$. For developing the decision framework, we review the recent published studies of green supplier selection $[10,12,14,26-28]$ to check the related criteria for each aspect.

Lee et al. [10] suggested that the framework of green supplier selection for high-tech industry should include six aspects and 23 criteria, but they presented a limited discussion of several important and traditional criteria, such as delivery, price, and financial stability. Kuo et al. [12] determined the green supplier selection criteria based on literatures and a Delphi expert questionnaire, presenting six aspects and 24 criteria, sent to ten experts. Tseng and Chiu [27] proposed 18 GSCM criteria through comprehensive discussion and literatures for a printed circuit board
TABLE 1: The criteria of the green supplier selection.

\begin{tabular}{lcc}
\hline Aspects & Criteria & $\begin{array}{c}\text { Relevant } \\
\text { references }\end{array}$ \\
\hline Environmental & $g_{1}:$ safety and health & {$[17]$} \\
factor & $g_{2}:$ strategic fit & {$[10]$} \\
& $g_{3}:$ environmental control & {$[14]$} \\
& $g_{4}:$ recovery & {$[26]$} \\
\hline Enterprise & $g_{5}:$ price & {$[12]$} \\
operating & $g_{6}:$ finance stability & {$[10]$} \\
& $g_{7}:$ quality control & {$[12]$} \\
& $g_{8}:$ out-of-control management & {$[12]$} \\
& $g_{9}:$ delivery & {$[14]$} \\
Strategic & $g_{10}:$ flexibility & {$[27]$} \\
technology and & $g_{13}:$ maintenance and support & {$[27]$} \\
development & $g_{14}:$ compatibility across levels & {$[14]$} \\
& $g_{15}:$ information share & {$[27]$} \\
\hline
\end{tabular}

manufacturer. Using the framework proposed by Tseng and Chiu's [27], we included supplier relation closeness in our proposed framework to carry out the suppliers' connection to green supplier selection. Supplier relation closeness is an important criterion in the supplier audit forms. It contains the implication of communication channels, information sharing, instant feedback, and resource-sharing platform among the suppliers of the supply chain. Lin [26] examined the cause and effect relationships among the eight criteria to evaluate GSCM practices using fuzzy DEMATEL. Because all of the criteria are related to GSCM practices, we adopted some environmental criteria in our proposed framework. Büyüközkan [14] described the framework of green supplier selection based on the literatures about automotive industry, including three aspects and 12 criteria. In sum, most of the published studies have developed a framework for green supplier selection based on previous studies and interviews, possibly because interviewing is the most convenient way to link the reviewed studies with the real cases. In this study, we develop a suitable decision framework of three aspects and 15 criteria for green supplier selection, as shown in Table 1.

\section{The Proposed Hybrid MCGDM Method}

To construct a systematic evaluation to support the process of green supplier selection, we propose a hybrid MCGDM method of four stages. The first stage evaluates the subjective criteria weights of each DM based on the AHP method. At the second stage, we consider entropy to evaluate the objective criteria weights of each DM. At the third stage, we use ELECTRE III to rank and improve the suppliers. For the fourth stage, LAM is used to integrate the ranking results of each DM based on the result of the third stage. Suppose a set of alternatives is $\left(a_{1}, \ldots, a_{i}, \ldots, a_{k}, \ldots, a_{m}\right)$ and the criteria are defined as $\left(g_{1}, \ldots, g_{j}, \ldots, g_{n}\right)$. There are a number of DMs 
denoted as $\left(D_{1}, \ldots, D_{t}, \ldots, D_{l}\right)$. The weights of each criterion for DMs are $w_{t j}$ and $x_{i j}$, representing the performance value of alternative $a_{i}$ under criterion $g_{j}$. The AHP method, the entropy method, the ELECTRE III method, and LAM are described as follows.

3.1. The AHP Method for Determining the Subjective Weights. Saaty $[39,40]$ used AHP to determine the DM's subjective weight in a hierarchical structure. All decision problems can be considered as having a hierarchical structure. The important advantage of AHP is that a decision problem can be decomposed into a number of subsystems [41], and a complicated decision problem can be systematized to a hierarchical structure. The hierarchical structure starts with a goal and then moves to the intermediate level, containing aspects and criteria, and the alternatives are at the bottom. In this study, the first level is the goal for the overall objectives of the problem for green supplier selection. The second level is decomposed into three aspects, and each aspect can also be decomposed into several criteria, as shown in Table 1. If the criteria at the low levels exist, the criteria at the lower levels can be generated based on the same principle. After constructing the hierarchical structure of the problem for green supplier selection, the next step is to survey the comparative weights among the aspects/criteria with a 19 point scale ranging from equally important to extremely important to build the comparison matrices. The subjective weight of criterion $j$ can be found with respect to the maximum eigenvalue of the comparative matrix for DM $t$, which can be expressed as $w_{t j}^{\prime}$. Then, we can further check the consistency index (C.I.) and consistency ratio (C.R.) of each comparison matrix via the following equation:

$$
\begin{gathered}
\text { C.I. }=\frac{\lambda_{\max }-n}{n-1}, \\
\text { C.R. }=\frac{\text { C.I. }}{\text { R.I. }}
\end{gathered}
$$

The C.I. and C.R. values should not be larger than 0.1 for a confident result. If C.I. or C.R. value is larger than 0.1, we will interview manager or assistant manager for the inconsistent comparative weight and further adjust the value.

\subsection{The Entropy Method for Determining Objective Weights.}

The entropy method is used to evaluate the objective weights, which is an important concept in information theory [42]. This concept measures the expected information content of a specific message [43]. If the entropy measure is larger, the information contained is less. Therefore, we can decide the objective weight of each criterion based on the information contained in the decision matrix. First, a decision matrix is a matrix whose elements express the performance of an alternative with respect to a criterion. Then, the decision matrix can be normalized in a linear manner, which can be described as

$$
r_{i j}=\frac{\tilde{x}_{i j}}{\max _{j} \tilde{x}_{i j}}, \quad i=1,2, \ldots, m, j=1,2, \ldots, n,
$$

where

$$
\tilde{x}_{i j}= \begin{cases}x_{i j}, & \text { if } g_{j} \text { is a benefit criterion, } \\ \frac{1}{x_{i j}}, & \text { if } g_{j} \text { is a cost criterion. }\end{cases}
$$

Then, the degree of diversification of the normalized decision matrix can be considered using the following equation:

$$
\delta_{j}=1+b \sum_{i=1}^{m} r_{i j} \ln r_{i j}, \quad j=1,2, \ldots, n
$$

where $b=1 / \ln m$ and $b$ is a constant.

Finally, the objective weight of criterion $j$ can be obtained as follows:

$$
w_{j}^{\prime \prime}=\frac{\delta_{j}}{\sum_{i=1}^{n} \delta_{j}}, \quad j=1,2, \ldots, n
$$

In this study, according to the subjective weights and objective weights, the compromised weights of criterion $j$ for DM $t$ can be expressed as

$$
w_{t j}=\frac{w_{t j}^{\prime} w_{j}^{\prime \prime}}{\sum_{j=1}^{n} w_{t j}^{\prime} w_{j}^{\prime \prime}}, \quad t=1,2, \ldots, l, j=1,2, \ldots, n
$$

\subsection{The ELECTRE III Method to Evaluate the Performance of} Suppliers. The ELECTRE III method, proposed by Roy [44], was designed to address inaccurate, imprecise, uncertain, or ill-determined data, such as qualitative data. ELECTRE III not only evaluates the best choice, but also presents a specific ranking result and leaves the final selection to the DMs. For the issue of green supplier selection, ELECTRE III is chosen as a suitable method, and it involves aspects that are often neglected by other methods for yielding relatively stable results [45]. Before we illustrate ELECTRE III, we define three threshold values that establish the DM's preference for each criterion $j$, including indifference, preference, and veto thresholds. The indifference threshold $\left(q_{j}\right)$ indicates a gap between the evaluation scores that are still compatible with a situation of indifference. The preference threshold $\left(p_{j}\right)$ expresses the minimum difference between the values of criterion $j$, to which the DM attributes significance in terms of strict preference. The veto threshold $\left(v_{j}\right)$ expresses the minimum difference between the values of criterion $j$ beyond which the DM believes the gap between the two scores cannot be compensated by the good performance of the other criteria. In this study, these thresholds for each criterion were set by interviews with DMs. Then, outranking degree can be defined as that alternative $i$ outranks alternative $k$ for $\mathrm{DM} t$, which can be calculated by the following equation:

$$
C_{t}\left(a_{i}, a_{k}\right)=\frac{1}{w} \sum_{j=1}^{n} w_{t j} c_{j}\left(a_{i}, a_{k}\right),
$$


where

$$
\begin{gathered}
w=\sum_{j=1}^{n} w_{t j}, \\
c_{j}\left(a_{i}, a_{k}\right)= \begin{cases}1, & \text { if } x_{i j}+q_{j} \geq x_{k j}, \\
0, & \text { if } x_{i j}+p_{j} \leq x_{k j}, \\
\frac{p_{j}+x_{i j}-x_{k j}}{p_{j}-q_{j}}, & \text { otherwise. }\end{cases}
\end{gathered}
$$

We then consider rejecting degree which means alternative $i$ is dominated by alternative $k$ under criterion $j$ as follows:

$$
\begin{aligned}
& d_{j}\left(a_{i}, a_{k}\right) \\
& = \begin{cases}1, & \text { if } g_{j}\left(a_{k}\right) \geq g_{j}\left(a_{i}\right)+v_{j} \\
0, & \text { if } g_{j}\left(a_{k}\right) \leq g_{j}\left(a_{i}\right)+p_{j} \\
\frac{g_{j}\left(a_{k}\right)-g_{j}\left(a_{i}\right)-p_{j}}{v_{j}-p_{j}}, & \text { otherwise. }\end{cases}
\end{aligned}
$$

Therefore, the overall outranking degree of DM $t$ can be considered with outranking degree and rejecting degree, which is called overall outranking degree as indicated in the following equation:

$$
\begin{aligned}
& S_{t}\left(a_{i}, a_{k}\right) \\
& =\left\{\begin{array}{cc}
C_{t}\left(a_{i}, a_{k}\right), & \text { if } d_{j}\left(a_{i}, a_{k}\right) \\
C_{t}\left(a_{i}, a_{k}\right) & \leq C_{t}\left(a_{i}, a_{k}\right) \forall j, \\
\times \prod_{j \in J\left(a_{i}, a_{k}\right)} \frac{1-d_{j}\left(a_{i}, a_{k}\right)}{1-C_{t}\left(a_{i}, a_{k}\right)}, & \text { otherwise, }
\end{array}\right.
\end{aligned}
$$

where $J\left(a_{i}, a_{k}\right)$ is the set of criteria such that $d_{j}\left(a_{i}, a_{k}\right)>$ $C_{t}\left(a_{i}, a_{k}\right)$.

The final step is to exploit the model and produce a ranking result from the overall outranking degrees. The general approach for exploitation is to construct two preorders $Z_{1}$ and $Z_{2}$ using the descending and ascending distillation process and then combine these two to produce a partial preorder $Z=Z_{1} \cap Z_{2}$. The descending process is to classify the alternatives from the best to the worst, while the ascending process is from the worst to the best [46-48].

3.4. The LAM for Integrating Ranking Results of DMs. Bernardo and Blin [31] developed LAM to transform individual ranking result into an overall ranking result. Therefore, LAM can integrate the ranking result of each DM into an overall ranking result. We can apply this simple method to sum the ranking score from each DM and rank the overall score from the lowest score to the highest score [43]. If an alternative is ranked as the first order, the alternative gets one point. If an alternative is ranked as the second, it gets two points, and so on. On the other hand, LAM also considers the weights of the DMs to integrate the overall ranking result. In our case study, we consider the weights of DMs based on their positions. For example, the R\&D department has approximately $27 \%$ of the decision-making power for green supplier selection, so the weight of the R\&D department is 0.27 in the procedure of green supplier selection. LAM can be illustrated as follows. First, an overall ranking matrix is established as $\Pi=\left[\pi_{i s}\right]$, where $\pi_{i s}$ represents the weighted frequency that $a_{i}$ is ranked the $s$ th with the different weights of the DMs. Then, depending on the above overall ranking matrix, we formulate a linear programming model to optimize the permutation. The linear programming model uses the binary decision variables $\varphi_{i s}$. The decision variable $\varphi_{i s}=1$ means $a_{i}$ is assigned to the sth overall rank and $\varphi_{i s}=0$ otherwise. Obviously, one alternative can be assigned to only one rank, and one rank can only be assigned by one alternative. Therefore, the linear programming model can be written as follows:

$$
\begin{aligned}
\max & \sum_{i=1}^{m} \sum_{f=1}^{m} \pi_{i s} \varphi_{i s} \\
\text { subject to } & \sum_{i=1}^{m} \varphi_{i s}=1, \quad s=1,2, \ldots, m, \\
& \sum_{f=1}^{m} \varphi_{i s}=1, \quad i=1,2, \ldots, m, \\
& \varphi_{i s} \in\{0,1\}, \quad i, s=1,2, \ldots, m .
\end{aligned}
$$

\section{Application Case}

Y-TECH is the first manufacturer in Taiwan to mass-produce TFT-LCD panels, and it is also one of the top five TFTLCD panel manufacturers in the world. By utilizing the data coming from Y-TECH, we aimed at providing a useful evaluation method with continuous improvement. Because of the global competitive market, the well-known TFTLCD manufacturers hope to develop and invest in their suppliers, especially for some of the important components for TFT-LCD panel, such as the color filter, back-light unit, and polarizer. Because good suppliers may affect the manufacturer's performance and competitiveness and the entire supply chain, in this study, we demonstrate the supplier evaluation procedure and provide information about supplier assistance for TFT-LCD manufacturers.

4.1. Study Background. In the polarizer industry, the polarizer manufacturer of the highest market share is in South Korea, while the Japanese polarizer manufacturer has the second highest market share. In recent years, Y-TECH mainly depended on materials and technical support from Japanese polarizer manufacturers. Also, the Korean polarizer manufacturers have aggressively intervened in the supply chain of Taiwanese TFT-LCD industry. Y-TECH has started to reconsider its supplier evaluation procedure and involved the group of GPM department in auditing and evaluating its suppliers. Figure 1 shows the new decision procedure for 


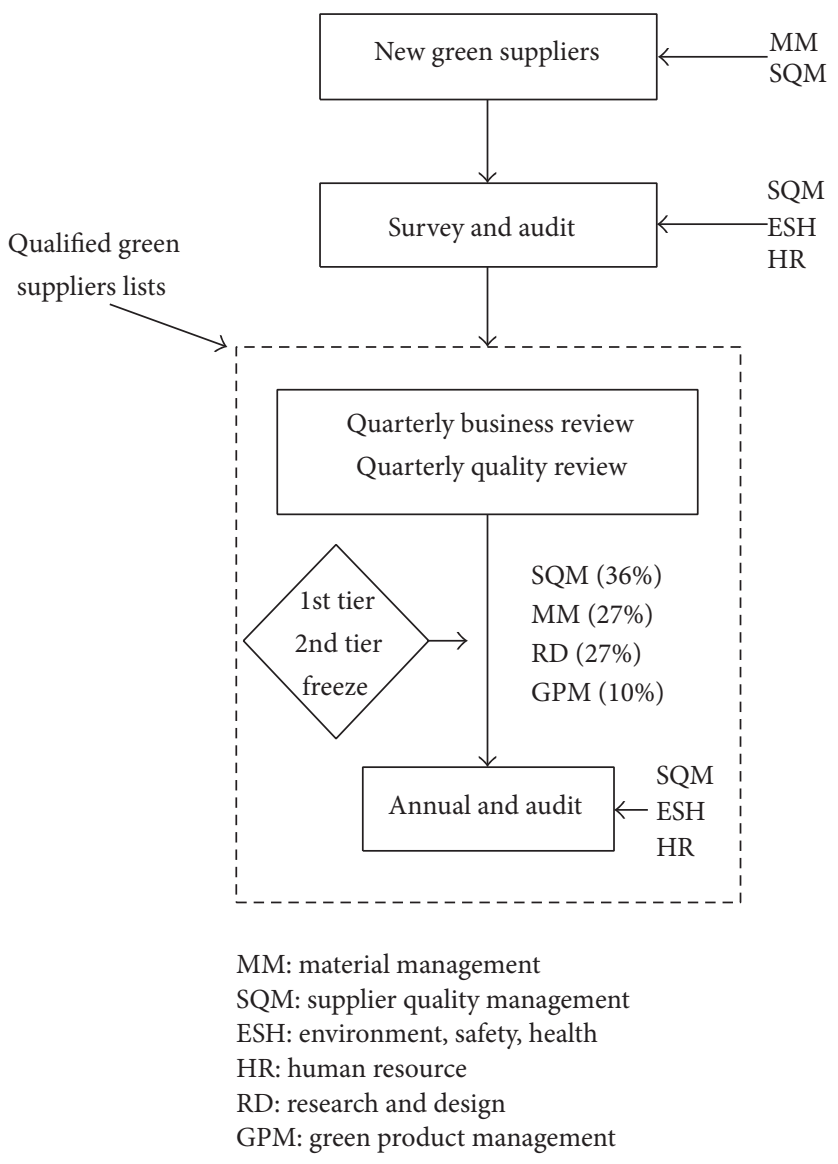

FIGURE 1: The decision procedure of green supplier selection in the case study.

green supplier selection at Y-TECH. Before being a formal polarizer supplier in Y-TECH, the candidate companies should pass a two-stage assessment. At the first stage, a new polarizer supplier should accept a preliminary survey by the teams of MM and SQM departments, and then the teams of SQM, ESH, and HR departments further execute the preliminary audit for the polarizer suppliers. A qualified polarizer manufacturera should pass at least $70 \%$ of the items on all supplier audit forms. At the second stage, the formal evaluation is conducted by the teams of SQM, MM, RD, and GPM departments. After the second-stage assessment, the qualified polarizer suppliers will be ranked in the first tier if they pass more than $80 \%$ of the items on supplier audit forms, and the suppliers, passing $70 \%-80 \%$ of the items, will be ranked in the second tier. If the qualified polarizer supplier passes fewer than $70 \%$ of the items, it will be regarded as disqualified. All of the formal suppliers are reviewed regularly by the teams of SQM, ESH, and HR departments. Furthermore, IS9001, ISO14001, and OHSAS18001 certifications are not necessary in the evaluation procedure because Y-TECH will assist their formal suppliers to apply for environmental certifications within a limited time. The first-stage assessment is the preliminary survey and audit, so we focus on applying the proposed MCGDM method to the formal evaluation for the assessment at the second stage.
In this case study, although four qualified polarizer suppliers for Y-TECH outperformed in all other suppliers for the first-stage survey, our focus will be on supplier 3 because it is a subsidiary company for Y-TECH. In fact, strategic purchase is an important strategy to enhance competitiveness in the TFT-LCD industry. Therefore, the decision procedure is not only to select the subsidiary into the supply chain but also to provide improvement reports for the subsidiary company. Additionally, it is expected that the subsidiary supplier will be the primary one. In addition to the three aspects and fifty criteria (as mentioned in Section 2), we also surveyed 12 managers on the expert committee. In practice, the SQM department holds $36 \%$ of the decision-making power, the MM and R\&D departments 27\%, and the GPM department $10 \%$ to select suitable suppliers during the decision-making process.

4.2. Empirical Results. First, we designed a questionnaire for 12 experts to measure the comparative weights between the aspects and criteria. Table 2 presents the subjective weights of each criterion for DMs based on AHP. The managers of MM, $\mathrm{RD}, \mathrm{GPM}$, and SQM departments are $\left\{D_{1}, D_{2}, D_{3}\right\},\left\{D_{4}, D_{5}\right\}$, $\left\{D_{6}, D_{7}, D_{8}, D_{9}\right\}$, and $\left\{D_{10}, D_{11}, D_{12}\right\}$, respectively. Then, we focused on the criteria weights that were 1.5 more than the average weight $(0.1)$. Notice that many managers think 
TABLE 2: Subjective weights of each criterion for DMs.

\begin{tabular}{lcccccccccccc}
\hline Dept. & & $M M$ & \multicolumn{3}{c}{$\mathrm{M}$} & \multicolumn{2}{c}{$\mathrm{RD}$} & \multicolumn{2}{c}{$\mathrm{GPM}$} & \multicolumn{2}{c}{ SQM } \\
Criteria & $D_{1}$ & $D_{2}$ & $D_{3}$ & $D_{4}$ & $D_{5}$ & $D_{6}$ & $D_{7}$ & $D_{8}$ & $D_{9}$ & $D_{10}$ & $D_{11}$ & $D_{12}$ \\
\hline$g_{1}$ & 0.014 & 0.192 & 0.009 & $\mathbf{0 . 1 7 7}$ & $\mathbf{0 . 3 4 9}$ & 0.007 & 0.106 & 0.111 & 0.120 & 0.006 & 0.117 & 0.022 \\
$g_{2}$ & 0.014 & 0.021 & 0.033 & $\mathbf{0 . 4 2 1}$ & $\mathbf{0 . 0 5 0}$ & 0.007 & 0.032 & 0.111 & 0.120 & $\mathbf{0 . 0 4 2}$ & $\mathbf{0 . 2 9 0}$ & $\mathbf{0 . 1 1 9}$ \\
$g_{3}$ & 0.036 & 0.043 & 0.012 & $\mathbf{0 . 0 8 3}$ & $\mathbf{0 . 1 7 4}$ & 0.037 & 0.048 & 0.056 & 0.033 & 0.016 & 0.036 & 0.044 \\
$g_{4}$ & 0.007 & 0.006 & 0.002 & $\mathbf{0 . 0 2 8}$ & $\mathbf{0 . 1 7 4}$ & 0.007 & 0.010 & 0.056 & 0.007 & 0.002 & 0.012 & 0.006 \\
$g_{5}$ & $\mathbf{0 . 4 0 5}$ & $\mathbf{0 . 0 0 6}$ & $\mathbf{0 . 0 4 8}$ & 0.016 & 0.009 & 0.131 & 0.093 & 0.093 & 0.004 & 0.019 & 0.011 & 0.017 \\
$g_{6}$ & 0.081 & 0.001 & 0.048 & 0.005 & 0.003 & 0.026 & 0.031 & 0.019 & 0.001 & 0.004 & 0.002 & 0.017 \\
$g_{7}$ & 0.039 & 0.043 & 0.048 & 0.071 & 0.057 & $\mathbf{0 . 1 3 1}$ & $\mathbf{0 . 1 9 7}$ & $\mathbf{0 . 0 5 6}$ & $\mathbf{0 . 0 2 5}$ & 0.161 & 0.029 & 0.007 \\
$g_{8}$ & 0.039 & 0.009 & 0.048 & 0.010 & 0.019 & 0.026 & 0.049 & 0.056 & 0.008 & 0.032 & 0.010 & 0.002 \\
$g_{9}$ & 0.064 & 0.009 & 0.045 & 0.006 & 0.015 & 0.071 & 0.073 & 0.079 & 0.010 & 0.007 & 0.016 & 0.002 \\
$g_{10}$ & 0.016 & 0.009 & 0.045 & 0.003 & 0.013 & 0.071 & 0.031 & 0.020 & 0.021 & 0.026 & 0.005 & 0.002 \\
$g_{11}$ & 0.007 & 0.002 & 0.006 & 0.001 & 0.004 & 0.014 & 0.019 & 0.013 & 0.003 & 0.044 & 0.018 & 0.001 \\
$g_{12}$ & $\mathbf{0 . 1 7 4}$ & $\mathbf{0 . 4 8 0}$ & $\mathbf{0 . 4 2 1}$ & 0.026 & 0.083 & $\mathbf{0 . 1 9 6}$ & $\mathbf{0 . 0 7 8}$ & $\mathbf{0 . 2 4 3}$ & $\mathbf{0 . 2 7 0}$ & $\mathbf{0 . 0 1 3}$ & $\mathbf{0 . 0 8 5}$ & $\mathbf{0 . 4 7 6}$ \\
$g_{13}$ & 0.058 & 0.096 & 0.070 & 0.130 & 0.028 & $\mathbf{0 . 1 9 6}$ & $\mathbf{0 . 1 5 5}$ & $\mathbf{0 . 0 4 9}$ & $\mathbf{0 . 2 7 0}$ & $\mathbf{0 . 0 9 3}$ & $\mathbf{0 . 2 5 6}$ & $\mathbf{0 . 1 5 9}$ \\
$g_{14}$ & 0.035 & 0.069 & 0.143 & 0.019 & 0.006 & 0.020 & 0.039 & 0.021 & 0.081 & 0.089 & 0.028 & 0.106 \\
$g_{15}$ & 0.012 & 0.014 & 0.020 & 0.004 & 0.017 & 0.059 & 0.039 & 0.021 & 0.027 & $\mathbf{0 . 4 4 5}$ & $\mathbf{0 . 0 8 5}$ & $\mathbf{0 . 0 2 1}$ \\
\hline
\end{tabular}

highly of the current capability $\left(g_{12}\right)$ and R\&D capability $\left(g_{13}\right)$. The managers of MM department generally place importance on the current capability $\left(g_{12}\right)$, and the weights of $D_{1}, D_{2}$, and $D_{3}$ are $0.174,0.480$, and 0.421 , respectively. Moreover, MM department is also concerned with the price $\left(g_{5}\right)$, and the average weight is 0.153 . It is generally agreed that the managers of $\mathrm{R} \& \mathrm{D}$ department put emphasis on environmental factors because of their relevance to product design. Taking strategic fit $\left(g_{2}\right)$, for example, suppliers should review environment-related substance list regularly when developing a green product. The average weights of safety and health $\left(g_{1}\right)$, strategic fit $\left(g_{2}\right)$, environmental control $\left(g_{3}\right)$, and recovery $\left(g_{4}\right)$ are $0.263,0.236,0.129$, and 0.101 , respectively, and the importance of environmental factors is over $70 \%$ of the total weight.

In particular, GPM department does not give more weight to environmental factors, and the average weight of environmental factors is only 0.054 . The most likely reason is that the GPM department holds less decision-making power. GPM department is concerned with quality control $\left(g_{7}\right)$, current capability $\left(g_{12}\right)$, and R\&D capability $\left(g_{13}\right)$, and the average weights are $0.102,0.196$, and 0.168 , respectively. Overall, the managers of GPM department are still concerned with the current capability $\left(g_{12}\right)$ and the R\&D capability $\left(g_{13}\right)$. Finally, SQM department focuses on the strategic fit $\left(g_{2}\right)$, current capability $\left(g_{12}\right)$, R\&D capability $\left(g_{13}\right)$, and information share $\left(g_{15}\right)$, and the average weights of these factors are $0.150,0.191,0.169$, and 0.184 , respectively. Based on our expectation, SQM department is not significantly concerned with quality control $\left(g_{7}\right)$ or other criteria of the enterprise operation, and the average weight for quality control $\left(g_{7}\right)$ is only 0.066 . However, SQM department emphasizes the importance of information share $\left(g_{15}\right)$. Information share brings the benefit of enhancing the competitiveness of the entire supply chain, especially technology development. In sum, SQM department focuses on the criteria of strategic
TABLE 3: Objective weights of each criterion for individual DM.

\begin{tabular}{lc}
\hline Criteria & Objective weights \\
\hline$g_{1}$ & 0.072 \\
$g_{2}$ & 0.076 \\
$g_{3}$ & 0.067 \\
$g_{4}$ & 0.066 \\
$g_{5}$ & 0.064 \\
$g_{6}$ & 0.075 \\
$g_{7}$ & 0.081 \\
$g_{8}$ & 0.078 \\
$g_{9}$ & 0.080 \\
$g_{10}$ & 0.064 \\
$g_{11}$ & 0.047 \\
$g_{12}$ & 0.050 \\
$g_{13}$ & 0.070 \\
$g_{14}$ & 0.056 \\
$g_{15}$ & 0.054 \\
\hline
\end{tabular}

technology and development. Thus, to avoid overly subjective weights, we include the entropy method in the proposed evaluation procedure using (2) through (5). The objective weights of the criteria are shown in Table 3 , while Table 4 indicates the compromised weights of the criteria for each DM by (6).

After the compromised criteria weights of the DMs are decided, we further apply the criteria weights and the performance to the ELECTRE III method, (7) through (10), to evaluate the four polarizer suppliers. For each DM, the outranking degree of any two alternatives can be calculated by (7), and the results are shown in Table 5. For example, for manager $D_{1}$, the outranking degree of alternative 1 to alternative 3 is 0.743 , and the outranking degree of alternative 3 to alternative 1 is 0.493 . Obviously, manager $D_{1}$ believes 
TABLE 4: Compromised weights of each criterion for DMs.

\begin{tabular}{lcccccccccccc}
\hline Dept. & \multicolumn{3}{c}{$\mathrm{MM}$} & \multicolumn{3}{c}{$\mathrm{M}$ R } & \multicolumn{3}{c}{$\mathrm{GPM}$} & \multicolumn{2}{c}{ SQM } \\
Criteria & $D_{1}$ & $D_{2}$ & $D_{3}$ & $D_{4}$ & $D_{5}$ & $D_{6}$ & $D_{7}$ & $D_{8}$ & $D_{9}$ & $D_{10}$ & $D_{11}$ & $D_{12}$ \\
\hline$g_{1}$ & 0.016 & 0.230 & 0.011 & 0.176 & 0.367 & 0.008 & 0.109 & 0.121 & 0.135 & 0.007 & 0.123 & 0.027 \\
$g_{2}$ & 0.016 & 0.027 & 0.042 & 0.441 & 0.055 & 0.008 & 0.035 & 0.127 & 0.142 & 0.051 & 0.322 & 0.152 \\
$g_{3}$ & 0.037 & 0.048 & 0.013 & 0.077 & 0.170 & 0.038 & 0.046 & 0.057 & 0.034 & 0.017 & 0.035 & 0.050 \\
$g_{4}$ & 0.007 & 0.007 & 0.002 & 0.025 & 0.168 & 0.007 & 0.009 & 0.056 & 0.007 & 0.002 & 0.012 & 0.007 \\
$g_{5}$ & 0.399 & 0.006 & 0.051 & 0.014 & 0.008 & 0.128 & 0.085 & 0.090 & 0.004 & 0.020 & 0.010 & 0.018 \\
$g_{6}$ & 0.093 & 0.001 & 0.060 & 0.005 & 0.003 & 0.030 & 0.033 & 0.022 & 0.001 & 0.005 & 0.002 & 0.021 \\
$g_{7}$ & 0.049 & 0.058 & 0.065 & 0.079 & 0.067 & 0.162 & 0.229 & 0.068 & 0.032 & 0.209 & 0.034 & 0.010 \\
$g_{8}$ & 0.047 & 0.012 & 0.062 & 0.011 & 0.022 & 0.031 & 0.055 & 0.066 & 0.010 & 0.040 & 0.011 & 0.003 \\
$g_{9}$ & 0.079 & 0.012 & 0.060 & 0.007 & 0.018 & 0.087 & 0.084 & 0.095 & 0.012 & 0.009 & 0.019 & 0.003 \\
$g_{10}$ & 0.016 & 0.010 & 0.048 & 0.003 & 0.012 & 0.069 & 0.028 & 0.019 & 0.021 & 0.027 & 0.005 & 0.002 \\
$g_{11}$ & 0.005 & 0.002 & 0.005 & 0.001 & 0.003 & 0.010 & 0.013 & 0.009 & 0.002 & 0.033 & 0.012 & 0.001 \\
$g_{12}$ & 0.134 & 0.400 & 0.350 & 0.018 & 0.061 & 0.149 & 0.056 & 0.183 & 0.211 & 0.010 & 0.062 & 0.401 \\
$g_{13}$ & 0.062 & 0.112 & 0.081 & 0.126 & 0.029 & 0.209 & 0.156 & 0.052 & 0.295 & 0.104 & 0.262 & 0.187 \\
$g_{14}$ & 0.030 & 0.064 & 0.133 & 0.015 & 0.005 & 0.017 & 0.031 & 0.018 & 0.071 & 0.08 & 0.023 & 0.100 \\
$g_{15}$ & 0.010 & 0.013 & 0.018 & 0.003 & 0.013 & 0.049 & 0.030 & 0.017 & 0.023 & 0.385 & 0.067 & 0.019 \\
\hline
\end{tabular}

TABLE 5: Outranking degrees of each DM.

\begin{tabular}{|c|c|c|c|c|c|c|c|c|c|c|c|c|c|c|}
\hline \multicolumn{5}{|c|}{$D_{1}$} & \multicolumn{5}{|c|}{$D_{2}$} & \multicolumn{5}{|c|}{$D_{3}$} \\
\hline & $a_{1}$ & $a_{2}$ & $a_{3}$ & $a_{4}$ & & $a_{1}$ & $a_{2}$ & $a_{3}$ & $a_{4}$ & & $a_{1}$ & $a_{2}$ & $a_{3}$ & $a_{4}$ \\
\hline$a_{1}$ & 0 & 0.588 & 0.743 & 0.867 & $a_{1}$ & 0 & 0.771 & 0.578 & 0.868 & $a_{1}$ & 0 & 0.688 & 0.547 & 0.844 \\
\hline$a_{2}$ & 0.521 & 0 & 0.598 & 0.633 & $a_{2}$ & 0.310 & 0 & 0.374 & 0.425 & $a_{2}$ & 0.409 & 0 & 0.442 & 0.529 \\
\hline$a_{3}$ & 0.493 & 0.538 & 0 & 0.762 & $a_{3}$ & 0.715 & 0.779 & 0 & 0.803 & $a_{3}$ & 0.669 & 0.719 & 0 & 0.763 \\
\hline$a_{4}$ & 0.591 & 0.619 & 0.479 & 0 & $a_{4}$ & 0.783 & 0.787 & 0.476 & 0 & $a_{4}$ & 0.771 & 0.735 & 0.488 & 0 \\
\hline \multicolumn{5}{|c|}{$D_{4}$} & \multicolumn{5}{|c|}{$D_{5}$} & \multicolumn{5}{|c|}{$D_{6}$} \\
\hline & $a_{1}$ & $a_{2}$ & $a_{3}$ & $a_{4}$ & & $a_{1}$ & $a_{2}$ & $a_{3}$ & $a_{4}$ & & $a_{1}$ & $a_{2}$ & $a_{3}$ & $a_{4}$ \\
\hline$a_{1}$ & 0 & 0.785 & 0.839 & 0.862 & $a_{1}$ & 0 & 0.790 & 0.804 & 0.858 & $a_{1}$ & 0 & 0.635 & 0.685 & 0.770 \\
\hline$a_{2}$ & 0.306 & 0 & 0.413 & 0.440 & $a_{2}$ & 0.378 & 0 & 0.444 & 0.463 & $a_{2}$ & 0.477 & 0 & 0.625 & 0.644 \\
\hline$a_{3}$ & 0.673 & 0.750 & 0 & 0.780 & $a_{3}$ & 0.650 & 0.678 & 0 & 0.703 & $a_{3}$ & 0.531 & 0.632 & 0 & 0.711 \\
\hline$a_{4}$ & 0.740 & 0.782 & 0.694 & 0 & $a_{4}$ & 0.745 & 0.832 & 0.643 & 0 & $a_{4}$ & 0.665 & 0.674 & 0.565 & 0 \\
\hline \multicolumn{5}{|c|}{$D_{7}$} & \multicolumn{5}{|c|}{$D_{8}$} & \multicolumn{5}{|c|}{$D_{9}$} \\
\hline & $a_{1}$ & $a_{2}$ & $a_{3}$ & $a_{4}$ & & $a_{1}$ & $a_{2}$ & $a_{3}$ & $a_{4}$ & & $a_{1}$ & $a_{2}$ & $a_{3}$ & $a_{4}$ \\
\hline$a_{1}$ & 0 & 0.642 & 0.762 & 0.767 & $a_{1}$ & 0 & 0.736 & 0.706 & 0.853 & $a_{1}$ & 0 & 0.762 & 0.664 & 0.864 \\
\hline$a_{2}$ & 0.473 & 0 & 0.602 & 0.634 & $a_{2}$ & 0.404 & 0 & 0.492 & 0.518 & $a_{2}$ & 0.320 & 0 & 0.465 & 0.520 \\
\hline$a_{3}$ & 0.534 & 0.604 & 0 & 0.667 & $a_{3}$ & 0.608 & 0.646 & 0 & 0.712 & $a_{3}$ & 0.634 & 0.788 & 0 & 0.809 \\
\hline$a_{4}$ & 0.687 & 0.663 & 0.628 & 0 & $a_{4}$ & 0.734 & 0.777 & 0.588 & 0 & $a_{4}$ & 0.702 & 0.735 & 0.532 & 0 \\
\hline \multicolumn{5}{|c|}{$D_{10}$} & \multicolumn{5}{|c|}{$D_{11}$} & \multicolumn{5}{|c|}{$D_{12}$} \\
\hline & $a_{1}$ & $a_{2}$ & $a_{3}$ & $a_{4}$ & & $a_{1}$ & $a_{2}$ & $a_{3}$ & $a_{4}$ & & $a_{1}$ & $a_{2}$ & $a_{3}$ & $a_{4}$ \\
\hline$a_{1}$ & 0 & 0.471 & 0.557 & 0.585 & $a_{1}$ & 0 & 0.762 & 0.754 & 0.841 & $a_{1}$ & 0 & 0.765 & 0.562 & 0.886 \\
\hline$a_{2}$ & 0.607 & 0 & 0.671 & 0.661 & $a_{2}$ & 0.326 & 0 & 0.491 & 0.509 & $a_{2}$ & 0.313 & 0 & 0.387 & 0.455 \\
\hline$a_{3}$ & 0.660 & 0.704 & 0 & 0.663 & $a_{3}$ & 0.630 & 0.776 & 0 & 0.791 & $a_{3}$ & 0.697 & 0.798 & 0 & 0.826 \\
\hline$a_{4}$ & 0.780 & 0.713 & 0.706 & 0 & $a_{4}$ & 0.704 & 0.761 & 0.644 & 0 & $a_{4}$ & 0.749 & 0.762 & 0.453 & 0 \\
\hline
\end{tabular}

that alternative 1 is superior to alternative 3. However, a characteristic of the ELECTRE III method is that a penalty is set if the alternative performs the worst for a criterion. Thus, we can use (9) to calculate the rejecting degree due to the penalty, and the overall outranking degree can be obtained by (10) as shown in Table 6. As another example, for the $D_{6}$ manager, the outranking degree of alternative 3 to alternative 2 is 0.632 , but the overall outranking degree of alternative 3 to alternative 2 is 0.000 . This means that alternative 3 performs too poorly to be accepted based on some criteria. The results presented in Table 7 show that alternative 3 performs too poorly on quality control $\left(g_{7}\right)$ and delivery $\left(g_{9}\right)$. The rejecting degrees for quality control $\left(g_{7}\right)$ and delivery $\left(g_{9}\right)$ are 1.000 and 0.778 , respectively, which 
TABLE 6: Overall outranking degree of each DM.

\begin{tabular}{|c|c|c|c|c|c|c|c|c|c|c|c|c|c|c|}
\hline \multicolumn{5}{|c|}{$D_{1}$} & \multicolumn{5}{|c|}{$D_{2}$} & \multicolumn{5}{|c|}{$D_{3}$} \\
\hline & $a_{1}$ & $a_{2}$ & $a_{3}$ & $a_{4}$ & & $a_{1}$ & $a_{2}$ & $a_{3}$ & $a_{4}$ & & $a_{1}$ & $a_{2}$ & $a_{3}$ & $a_{4}$ \\
\hline$a_{1}$ & 0 & 0.588 & 0.743 & 0.867 & $a_{1}$ & 0 & 0.771 & 0.564 & 0.868 & $a_{1}$ & 0 & 0.688 & 0.246 & 0.844 \\
\hline$a_{2}$ & 0.342 & 0 & 0.331 & 0.633 & $a_{2}$ & 0.026 & 0 & 0 & 0.148 & $a_{2}$ & 0.115 & 0 & 0 & 0.415 \\
\hline$a_{3}$ & 0.273 & 0.334 & 0 & 0.762 & $a_{3}$ & 0.715 & 0.779 & 0 & 0.803 & $a_{3}$ & 0.669 & 0.719 & 0 & 0.763 \\
\hline$a_{4}$ & 0.563 & 0 & 0.384 & 0 & $a_{4}$ & 0.783 & 0.787 & 0.361 & 0 & $a_{4}$ & 0.771 & 0.735 & 0.207 & 0 \\
\hline \multicolumn{5}{|c|}{$D_{4}$} & \multicolumn{5}{|c|}{$D_{5}$} & \multicolumn{5}{|c|}{$D_{6}$} \\
\hline & $a_{1}$ & $a_{2}$ & $a_{3}$ & $a_{4}$ & & $a_{1}$ & $a_{2}$ & $a_{3}$ & $a_{4}$ & & $a_{1}$ & $a_{2}$ & $a_{3}$ & $a_{4}$ \\
\hline$a_{1}$ & 0 & 0.785 & 0.839 & 0.862 & $a_{1}$ & 0 & 0.790 & 0.804 & 0.858 & $a_{1}$ & 0 & 0.245 & 0.483 & 0.746 \\
\hline$a_{2}$ & 0 & 0 & 0 & 0 & $a_{2}$ & 0 & 0 & 0 & 0.037 & $a_{2}$ & 0.090 & 0 & 0 & 0.644 \\
\hline$a_{3}$ & 0.673 & 0.750 & 0 & 0.780 & $a_{3}$ & 0.413 & 0.468 & 0 & 0.526 & $a_{3}$ & 0.091 & 0 & 0 & 0.546 \\
\hline$a_{4}$ & 0.633 & 0.782 & 0.694 & 0 & $a_{4}$ & 0.745 & 0.832 & 0.643 & 0 & $a_{4}$ & 0 & 0.459 & 0.541 & 0 \\
\hline \multicolumn{5}{|c|}{$D_{7}$} & \multicolumn{5}{|c|}{$D_{8}$} & \multicolumn{5}{|c|}{$D_{9}$} \\
\hline & $a_{1}$ & $a_{2}$ & $a_{3}$ & $a_{4}$ & & $a_{1}$ & $a_{2}$ & $a_{3}$ & $a_{4}$ & & $a_{1}$ & $a_{2}$ & $a_{3}$ & $a_{4}$ \\
\hline$a_{1}$ & 0 & 0.413 & 0.762 & 0.767 & $a_{1}$ & 0 & 0.736 & 0.706 & 0.853 & $a_{1}$ & 0 & 0.762 & 0.664 & 0.864 \\
\hline$a_{2}$ & 0.054 & 0 & 0.336 & 0.634 & $a_{2}$ & 0.037 & 0 & 0 & 0.163 & $a_{2}$ & 0.005 & 0 & 0 & 0.166 \\
\hline$a_{3}$ & 0.094 & 0 & 0 & 0.445 & $a_{3}$ & 0.344 & 0.406 & 0 & 0.550 & $a_{3}$ & 0.372 & 0.788 & 0 & 0.809 \\
\hline$a_{4}$ & 0 & 0.437 & 0.628 & 0 & $a_{4}$ & 0.734 & 0.774 & 0.588 & 0 & $a_{4}$ & 0 & 0.735 & 0.474 & 0 \\
\hline \multicolumn{5}{|c|}{$D_{10}$} & \multicolumn{5}{|c|}{$D_{11}$} & \multicolumn{5}{|c|}{$D_{12}$} \\
\hline & $a_{1}$ & $a_{2}$ & $a_{3}$ & $a_{4}$ & & $a_{1}$ & $a_{2}$ & $a_{3}$ & $a_{4}$ & & $a_{1}$ & $a_{2}$ & $a_{3}$ & $a_{4}$ \\
\hline$a_{1}$ & 0 & 0.072 & 0.123 & 0 & $a_{1}$ & 0 & 0.762 & 0.754 & 0.841 & $a_{1}$ & 0 & 0.765 & 0.509 & 0.886 \\
\hline$a_{2}$ & 0.607 & 0 & 0.671 & 0.661 & $a_{2}$ & 0 & 0 & 0 & 0 & $a_{2}$ & 0.034 & 0 & 0 & 0.261 \\
\hline$a_{3}$ & 0.660 & 0.529 & 0 & 0.663 & $a_{3}$ & 0.365 & 0.776 & 0 & 0.791 & $a_{3}$ & 0.697 & 0.798 & 0 & 0.826 \\
\hline$a_{4}$ & 0.780 & 0.713 & 0.706 & 0 & $a_{4}$ & 0 & 0.761 & 0.644 & 0 & $a_{4}$ & 0.664 & 0.762 & 0.315 & 0 \\
\hline
\end{tabular}

TABLE 7: Rejecting degree for alternative 3 to alternative 2 from $d_{6}$ manager.

\begin{tabular}{|c|c|c|c|c|c|c|c|c|c|c|c|c|c|c|c|}
\hline & $g_{1}$ & $g_{2}$ & $g_{3}$ & $g_{4}$ & $g_{5}$ & $g_{6}$ & $g_{7}$ & $g_{8}$ & $g_{9}$ & $g_{10}$ & $g_{11}$ & $g_{12}$ & $g_{13}$ & $g_{14}$ & $g_{15}$ \\
\hline Reject degree & 0.000 & 0.000 & 0.000 & 0.583 & 0.407 & 0.000 & 1.000 & 0.288 & 0.778 & 0.000 & 0.000 & 0.000 & 0.000 & 0.000 & 0.000 \\
\hline
\end{tabular}

are obviously larger than the outranking degree of 0.632 . In the next section, we further discuss which criteria should be improved immediately. Accordingly, we can establish the descending and ascending distillation for each DM, and the ranking results are shown in Table 8.

Finally, LAM is applied to establish linear programming for integrating the opinions of each DM. According to the decision-making power of each department, the overall ranking matrix is shown as follows:

$$
\Pi=\left[\begin{array}{llll}
0.6850 & 0.1950 & 0.0000 & 0.1200 \\
0.0400 & 0.1350 & 0.0850 & 0.7400 \\
0.2350 & 0.4700 & 0.2825 & 0.0125 \\
0.0400 & 0.2000 & 0.6325 & 0.1275
\end{array}\right]
$$

Therefore, we can formulate a linear programming model using (11) and obtain the solution, which indicates that the overall ranking result is $a_{1}>a_{3}>a_{4}>a_{2}$. The best supplier is supplier 1, and the subsidiary company of Y-TECH is second only to supplier 1 . Supplier 4 is ranked third, and supplier 2 performs the worst in this evaluation.
4.3. Discussion and Implications. In this study, we aim to propose a hybrid MCGDM method to evaluate and assist suppliers. At the first stage, we use the AHP method to measure the subjective weights of the criteria for each DM. Based on the results of the AHP method, it is obvious that most of the managers value the importance of current capability and $\mathrm{R} \& \mathrm{D}$ capability, and this suggests that Y-TECH places a great emphasis on technology development. In the FPD industry, due to the rapid development of new technology, many wellknown enterprises regularly release new products to market every year. A challenge for Y-TECH includes the development of other technologies, such as organic light-emitting displays (OLED). For example, the OLED panel led to the reduction of the demand for small and medium TFT-LCD displays in the global market in 2010. Therefore, to enhance competitiveness, TFT-LCD manufactures connecting with the suppliers in the entire supply chain should continuously develop new technology. Quality control is an important criterion secondary only to technological capability. At the early stages of applying a new technology to a new product, the yield rate of the new product is low. Consequently, it is important not only to develop the new technology, but also to maintain a highly qualified product. Currently, because 
TABLE 8: Initial evaluation of individual DM.

\begin{tabular}{lccccccccccrr}
\hline Dept. & & MM & \multicolumn{3}{c}{ RD } & \multicolumn{3}{c}{ GPM } & \multicolumn{3}{c}{ SQM } \\
Ranking & $d_{1}$ & $d_{2}$ & $d_{3}$ & $d_{4}$ & $d_{5}$ & $d_{6}$ & $d_{7}$ & $d_{8}$ & $d_{9}$ & $d_{10}$ & $d_{11}$ \\
\hline 1st & $a_{1}$ & $a_{1}, a_{3}$ & $a_{3}$ & $a_{1}$ & $a_{1}$ & $a_{1}$ & $a_{1}$ & $a_{1}$ & $a_{1}$ & $a_{2}, a_{3}, a_{4}$ & $a_{1}$ \\
2nd & $a_{2}, a_{3}$ & & $a_{1}$ & $a_{3}$ & $a_{4}$ & $a_{2}$ & $a_{2}$ & $a_{4}$ & $a_{3}$ & $a_{3}, a_{4}$ \\
3rd & & $a_{4}$ & $a_{4}$ & $a_{4}$ & $a_{3}$ & $a_{3}$ & $a_{3}, a_{4}$ & $a_{3}$ & $a_{4}$ & $a_{4}$ \\
4th & $a_{4}$ & $a_{2}$ & $a_{2}$ & $a_{2}$ & $a_{2}$ & $a_{4}$ & & $a_{2}$ & $a_{2}$ & $a_{1}$ & $a_{2}$ & $a_{2}$ \\
\hline
\end{tabular}

TABLE 9: The worst performing criteria of each alternative.

\begin{tabular}{lllll}
\hline & $a_{1}$ & $a_{2}$ & $a_{3}$ & $a_{4}$ \\
\hline$D_{1}$ & - & - & - & $g_{5}$ \\
$D_{2}$ & - & $g_{12}$ & - & - \\
$D_{3}$ & - & $g_{12}$ & - & - \\
$D_{4}$ & - & $g_{2}$ & - & - \\
$D_{5}$ & - & $g_{1}$ & - & - \\
$D_{6}$ & - & $g_{12}$ & $\mathbf{g}_{7}$ & $g_{13}$ \\
$D_{7}$ & - & - & $\mathbf{g}_{7}$ & $g_{13}$ \\
$D_{8}$ & - & $g_{12}$ & - & - \\
$D_{9}$ & - & $g_{12}$ & - & $g_{13}$ \\
$D_{10}$ & $\mathbf{g}_{15}$ & - & - & - \\
$D_{11}$ & - & $g_{2}$ & - & $g_{13}$ \\
$D_{12}$ & - & $g_{12}$ & - & - \\
\hline
\end{tabular}

GPM department processes less decision-making power for green supplier selection, it is obvious that environmental factors are not significantly considered in the evaluation procedure with the exception that R\&D department should design new products, and the related materials must be listed for MM department. Then, MM department can place an order and ask the suppliers to follow the list. SQM department is concerned with technological capability as well as information share. Vertical integration is an important enterprise policy for the TFT-LCD industry, and strategic purchase is a method for the implementation of vertical integration. As mentioned before, the key components of TFT-LCD panels that are produced in-house have gradually increased year by year, so information share is also an important criterion for cultivating the core capability of enterprise and establishing a competitive advantage. Furthermore, all of the criteria play important roles in the evaluation procedure for green supplier selection. If the proposed hybrid MCGDM method only adopts the AHP method, it will most likely lead to the oversubjective weighting of the criteria. Therefore, we apply the entropy method to consider the weights of the criteria simultaneously.

ELECTRE III is applied to evaluate the suppliers. During the evaluation procedure, we compare the outranking degree and the overall outranking degree and then decide which criterion should be improved immediately for each alternative, as shown in Table 9. If the overall outranking degree of a criterion decreases to zero (comparing to outranking degree), this criterion should be improved immediately. For the best supplier, supplier $1\left(a_{1}\right)$, the $D_{10}$ manager suggests that alternative 1 should strengthen communication with YTECH by taking actions such as improving cooperation for the development of new products and instant market information share $\left(g_{15}\right)$. In this case study, one of the most important aspects is how to provide assistance to the subsidiary company $\left(a_{3}\right)$ of Y-TECH. Table 9 indicates that if supplier 3 improves quality control $\left(g_{7}\right)$ for polarizer production, its performance will be improved significantly. Generally, it is contended that managers should be concerned about criteria related to their job description. Due to limited enterprise resources, the order of executing enterprise improvement is also an important issue. Following the useful proposed method, the discovery of the criteria that need to be improved will become easy.

Different from many previous studies, this study does not integrate the weights of the criteria at the first stage. In fact, green supplier selection is a group decision-making problem, and integrating the weights would also lead to the loss of information. Therefore, we further consider the ranking results of each department as shown in Table 10. Although these four polarizer manufacturers are the suppliers of Y-TECH, there are some differences among the ranking results of each department, especially for suppliers 2 and 4 . As mentioned before, $R \& D$ department placed great emphasis on the "green" criteria, and supplier 4's good performance on these criteria is the reason for the different ranking results. Consequently, in this study, we proposed a novel method and viewpoint for green supplier selection, and we suggested that the weights of the criteria should not be integrated at the first stage because further discussions and communication are necessary to include the different opinions from each department. Additionally, we compare the results of the proposed method with the ones implemented by Y-TECH, that is, simple additive method in Table 10. Both results show that supplier 1 has the best performance and is superior to supplier 3. Supplier 4 is in the third place, while supplier 2 is the worst. Furthermore, within the extensive literature on green supplier selection methods, the TOPSIS method was widely applied to evaluate green suppliers' performance $[15,17-22]$. Thus, we further compare the TOPSIS method with the proposed method, and the comparison is established on the basis of AHP-entropy criteria weights. In the TOPSIS method with AHP-entropy weights, supplier 3 is in the first place and superior to supplier 1 , and supplier 4 and supplier 2 have the worst performance in this evaluation. Although the ranking results among the proposed method and other two methods are similar, the emphasis of this study is on how to improve the suppliers' performance in the TFTLCD industry. More importantly, the results of the proposed 
TABLE 10: Comparison of ranking results for the proposed method with other methods.

\begin{tabular}{lccccccc}
\hline Ranking & MM & RD & GPM & SQM & The proposed method & Current method & AHP-entropy TOPSIS \\
\hline 1st & $a_{3}$ & $a_{1}$ & $a_{1}$ & $a_{1}$ & $a_{1}$ & $a_{1}$ & $a_{3}$ \\
2nd & $a_{1}$ & $a_{4}$ & $a_{2}$ & $a_{3}$ & $a_{3}$ & $a_{3}$ & $a_{1}$ \\
3rd & $a_{4}$ & $a_{3}$ & $a_{3}$ & $a_{4}$ & $a_{4}$ & $a_{4}$ & $a_{4}$ \\
4th & $a_{2}$ & $a_{2}$ & $a_{4}$ & $a_{2}$ & $a_{2}$ & $a_{2}$ & $a_{2}$ \\
\hline
\end{tabular}

The current evaluation method in Y-TECH is simple additive method.

method show that each department has its different opinions and viewpoints of improvement. Each department of the TFT-LCD manufacturers can assist their suppliers within the context of business perspectives.

\section{Conclusion}

In this study, we propose a hybrid MCGDM method for green supplier selection for Y-TECH. Our method focuses on not only the selection or ranking, but also the providence of assistance to suppliers to strengthen their competitiveness. This method also emphasizes continuous improvement. Due to the challenges and difficulties the TFT-LCD industries worldwide face, we intend to establish a systematic selection procedure for TFT-LCD manufacturers. We developed a decision framework for green supplier selection based on literatures and the supplier audit forms from Y-TECH. We considered AHP and the entropy method to measure the compromised weights of the criteria that involve subjective and objective opinions simultaneously. After that, the ELECTRE III method provides polarizer manufacturers' ranking results for executive managers in addition to improvement reports. The acquisition of key components used for inhouse production of TFT-LCD panels has gradually become a strategy for cost reduction and the enhancement of core capability. Thus, TFT-LCD manufacturers should strengthen their cooperation with their suppliers.

Based on the results of the ELECTRE III method, we can compare the differences between the outranking degree and the overall outranking degree. Then, we further consider which criteria should be improved immediately, especially for the suppliers of strategic purchases. The results of this study provide an important reference for subsidiary companies that are seeking to be primary polarizer suppliers. Finally, differing from many of the previous studies, we do not integrate the weights of the criteria with regard to a single DM in this study. In other worlds, we integrate the ranking results of each DM instead of the weights of the criteria. In the proposed evaluation procedure, LAM places more emphasis on the discussion and communication among a group of DMs, which is consistent with the practical case.

In summary, the result of this study can be regarded as a problem-solving process for green supplier selection. Regardless of the proposed method or analytic procedure, we aim at helping TFT-LCD manufacturers to establish a systematic and useful evaluation procedure via the current study. Because all of the supplier audit forms are in Microsoft
Excel 2010 spreadsheets, the proposed method is easy to apply using the same file. Executive managers can consider the performance of all suppliers and refer to the results of the proposed method. Three main contributions are made in this study. First, depending on the literatures and supplier audit forms, we develop a decision framework for the TFTLCD industry. Second, we propose the useful, systematic, and flexible hybrid MCGDM method (based on the business process) and improve the current evaluation procedure. Third, we place more emphasis on improving suppliers to enhance the competitiveness of entire supply chain, especially the subsidiary company. In practice, green supplier selection is evaluated by each department separately, and all criteria are regarded as independent. In recent years, increasing attention has been given to the interdependent relationships among the criteria $[15,16,26,49]$. Therefore, future studies are necessary to clarify the interrelations among the criteria. We hope that more detailed information influencing the relationships between the criteria can be provided in future research. Consequently, it would be more efficient to improve the supplier selection process for the entire supply chain in the future work.

\section{Conflict of Interests}

The authors declare that there is no conflict of interests regarding the publication of this paper.

\section{Acknowledgments}

This research was partially supported by the National Science Council of the Republic of China (Grant NSC 102-2221E-007-084). The authors would like to thank the editor and anonymous referees for their valuable comments and suggestions.

\section{References}

[1] Taiwan Stock Exchange, "Industry analysis: the flat panel display Industry," February 2013, http://www.twse.com.tw/ch/ products/publication/essay.php.

[2] S. Hung, "Competitive strategies for Taiwan's thin film transistor-liquid crystal display (TFT-LCD) industry," Technology in Society, vol. 28, no. 3, pp. 349-361, 2006.

[3] W. Ho, X. Xu, and P. K. Dey, "Multi-criteria decision making approaches for supplier evaluation and selection: a literature review," European Journal of Operational Research, vol. 202, no. 1, pp. 16-24, 2010. 
[4] J. Chai, J. N. K. Liu, and E. W. T. Ngai, "Application of decisionmaking techniques in supplier selection: a systematic review of literature," Expert Systems with Applications, vol. 40, no. 10, pp. 3872-3885, 2013.

[5] K. Govindan, S. Rajendran, J. Sarkis, and P. Murugesan, "Multi criteria decision making approaches for green supplier evaluation and selection: a literature review," Journal of Cleaner Production, 2013.

[6] M. Herva and E. Roca, "Review of combined approaches and multi-criteria analysis for corporate environmental evaluation," Journal of Cleaner Production, vol. 39, pp. 355-371, 2013.

[7] S. Seuring, "A review of modeling approaches for sustainable supply chain management," Decision Support Systems, vol. 54, no. 4, pp. 1513-1520, 2013.

[8] M. Igarashi, L. De Boer, and A. M. Fet, "What is required for greener supplier selection? A literature review and conceptual model development," Journal of Purchasing and Supply Management, vol. 19, no. 4, pp. 247-263, 2013.

[9] A. Genovese, S. C. Koh, G. Bruno, and E. Esposito, "Greener supplier selection: state of the art and some empirical evidence," International Journal of Production Research, vol. 51, no. 10, pp. 2868-2886, 2013.

[10] A. H. I. Lee, H. Y. Kang, C. F. Hsu, and H. C. Hung, "A green supplier selection model for high-tech industry," Expert Systems with Applications, vol. 36, no. 4, pp. 7917-7927, 2009.

[11] G. Tuzkaya, A. Ozgen, D. Ozgen, and U. R. Tuzkaya, "Environmental performance evaluation of suppliers: a hybrid fuzzy multi-criteria decision approach," International Journal of Environmental Science and Technology, vol. 6, no. 3, pp. 477-490, 2009.

[12] R. J. Kuo, Y. C. Wang, and F. C. Tien, "Integration of artificial neural network and MADA methods for green supplier selection," Journal of Cleaner Production, vol. 18, no. 12, pp. 1161-1170, 2010.

[13] Q. Zhu, Y. Dou, and J. Sarkis, "A portfolio-based analysis for green supplier management using the analytical network process," Supply Chain Management, vol. 15, no. 4, pp. 306-319, 2010.

[14] G. Büyüközkan, "An integrated fuzzy multi-criteria group decision-making approach for green supplier evaluation," International Journal of Production Research, vol. 50, no. 11, pp. 28922909, 2012.

[15] G. Büyüközkan and G. Çifçi, "A novel hybrid MCDM approach based on fuzzy DEMATEL, fuzzy ANP and fuzzy TOPSIS to evaluate green suppliers," Expert Systems with Applications, vol. 39, no. 3, pp. 3000-3011, 2012.

[16] C. H. Hsu, F. K. Wang, and G. H. Tzeng, "The best vendor selection for conducting the recycled material based on a hybrid MCDM model combining DANP with VIKOR," Resources, Conservation and Recycling, vol. 66, pp. 95-111, 2012.

[17] K. Govindan, R. Khodaverdi, and A. Jafarian, "A fuzzy multi criteria approach for measuring sustainability performance of a supplier based on triple bottom line approach," Journal of Cleaner Production, vol. 47, pp. 345-354, 2013.

[18] L. Shen, L. Olfat, K. Govindan, R. Khodaverdi, and A. Diabat, "A fuzzy multi criteria approach for evaluating green supplier's performance in green supply chain with linguistic preferences," Resources, Conservation and Recycling, vol. 74, pp. 170-179, 2013.

[19] M. Yazdani, "An integrated MCDM approach to green supplier selection," International Journal of Industrial Engineering Computations, vol. 5, no. 3, pp. 443-458, 2014.
[20] T. Chen and J. Freeman, "Using AHP-Entropy weight and TOPSIS methodology in green supplier selection," in Proceedings of the European Operations Management Association Conference (EurOMA '14), Palermo, Italy, June 2014.

[21] D. Kannan, A. B. L. D. S. Jabbour, and C. J. C. Jabbour, "Selecting green suppliers based on GSCM practices: using fuzzy TOPSIS applied to a Brazilian electronics company," European Journal of Operational Research, vol. 233, no. 2, pp. 432-447, 2014.

[22] H. Zhao and S. Guo, "Selecting green supplier of thermal power equipment by using a Hybrid MCDM Method for sustainability," Sustainability, vol. 6, no. 1, pp. 217-235, 2014.

[23] J. Figueira, S. Greco, and M. Ehrgott, Multiple Criteria Decision Analysis: State of the Art Surveys, Springer Science, Boston, Mass, USA, 2005.

[24] B. Roy, "The outranking approach and the foundations of ELECTRE methods," Theory and Decision, vol. 31, no. 1, pp. 4973, 1991.

[25] J. Hokkanen and P. Salminen, "Choosing a solid waste management system using multicriteria decision analysis," European Journal of Operational Research, vol. 98, no. 1, pp. 19-36, 1997.

[26] R. J. Lin, "Using fuzzy DEMATEL to evaluate the green supply chain management practices," Journal of Cleaner Production, vol. 40, pp. 32-39, 2013.

[27] M. L. Tseng and A. S. F. Chiu, "Evaluating firm's green supply chain management in linguistic preferences," Journal of Cleaner Production, vol. 40, pp. 22-31, 2013.

[28] G. Büyüközkan and G. Çifçi, "A novel fuzzy mulati -criteria decision framework for sustainable supplier selection with incomplete information," Computers in Industry, vol. 62, no. 2, pp. 164-174, 2011.

[29] M. T. Escobar and J. M. Moreno-Jiménez, "Aggregation of individual preference structures in AHP-group decision making," Group Decision and Negotiation, vol. 16, no. 4, pp. 287-301, 2007.

[30] V. Tsyganok, "Investigation of the aggregation effectiveness of expert estimates obtained by the pairwise comparison method," Mathematical and Computer Modelling, vol. 52, no. 3-4, pp. 538$544,2010$.

[31] J. J. Bernardo and J. M. Blin, "A programming model of consumer choice among multi-attributed brands," Journal of Consumer Research, vol. 4, no. 2, pp. 111-118, 1977.

[32] P. K. Humphreys, Y. K. Wong, and F. T. S. Chan, "Integrating environmental criteria into the supplier selection process," Journal of Materials Processing Technology, vol. 138, no. 1-3, pp. 349-356, 2003.

[33] C. Bai and J. Sarkis, "Integrating sustainability into supplier selection with grey system and rough set methodologies," International Journal of Production Economics, vol. 124, no. 1, pp. 252-264, 2010.

[34] X. Fu, Q. Zhu, and J. Sarkis, "Evaluating green supplier development programs at a telecommunications systems provider," International Journal of Production Economics, vol. 140, no. 1, pp. 357-367, 2012.

[35] A. Amindoust, S. Ahmed, A. Saghafinia, and A. Bahreininejad, "Sustainable supplier selection: a ranking model based on fuzzy inference system," Applied Soft Computing Journal, vol. 12, no. 6, pp. 1668-1677, 2012.

[36] K. Shaw, R. Shankar, S. S. Yadav, and L. S. Thakur, "Supplier selection using fuzzy AHP and fuzzy multi-objective linear programming for developing low carbon supply chain," Expert Systems with Applications, vol. 39, no. 9, pp. 8182-8192, 2012. 
[37] A. Awasthi, S. S. Chauhan, and S. K. Goyal, "A fuzzy multicriteria approach for evaluating environmental performance of suppliers," International Journal of Production Economics, vol. 126, no. 2, pp. 370-378, 2010.

[38] T. Y. Chiou, H. K. Chan, F. Lettice, and S. H. Chung, "The influence of greening the suppliers and green innovation on environmental performance and competitive advantage in Taiwan," Transportation Research Part E: Logistics and Transportation Review, vol. 47, no. 6, pp. 822-836, 2011.

[39] T. L. Saaty, "A scaling method for priorities in hierarchical structures," Journal of Mathematical Psychology, vol. 15, no. 3, pp. 234-281, 1977.

[40] T. L. Saaty, The Analytic Hierarchy Process, McGraw-Hill, New York, NY, USA, 1980.

[41] C. Macharis, J. Springael, K. De Brucker, and A. Verbeke, "PROMETHEE and AHP: the design of operational synergies in multicriteria analysis. Strengthening PROMETHEE with ideas of AHP," European Journal of Operational Research, vol. 153, no. 2, pp. 307-317, 2004.

[42] M. Zeleny, Multiple Criteria Decision Making, McGraw-Hill, New York, NY, USA, 1982.

[43] C. L. Hwang and K. Yoon, Multiple Attribute Decision Making Methods and Applications: A State-of-the-Art Survey, Springer, New York, NY. USA, 1981.

[44] B. Roy, "ELECTRE III: un algorithme de classements fondé sur une repré sentation floue des préférences en préferences en presence de critéres multiples," Cahiers du Centre d'Etudes de Recherche Opérationnelle, vol. 20, no. 1, pp. 3-24, 1978.

[45] P. Vincke, Multiple Criteria Decision-Aid, John Wiley \& Sons, Chichester, UK, 1992.

[46] M. Rogers and M. Bruen, "Using ELECTRE III to choose route for Dublin Port motorway," Journal of Transportation Engineering, vol. 126, no. 4, pp. 313-323, 2000.

[47] M. Rogers and M. Bruen, ELECTRE and Decision Support: Methods and Applications in Engineering and Infrastructure Investment, Kluwer Academic Publishers, Boston, Mass, USA, 2000.

[48] V. Belton and T. J. Stewart, Multiple Criteria Decision Analysis: An Integrated Approach, Kluwer Academic Publishers, Boston, Mass, USA, 2002.

[49] B. Chang, C. W. Chang, and C. H. Wu, "Fuzzy DEMATEL method for developing supplier selection criteria," Expert Systems with Applications, vol. 38, no. 3, pp. 1850-1858, 2011. 


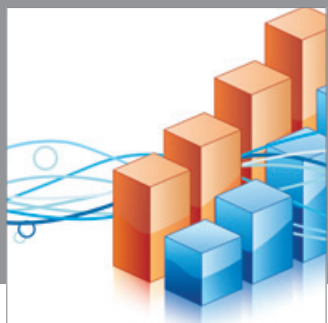

Advances in

Operations Research

mansans

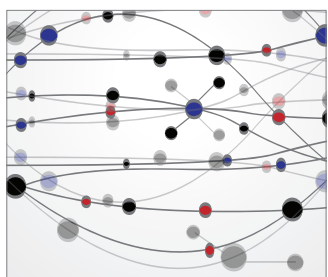

The Scientific World Journal
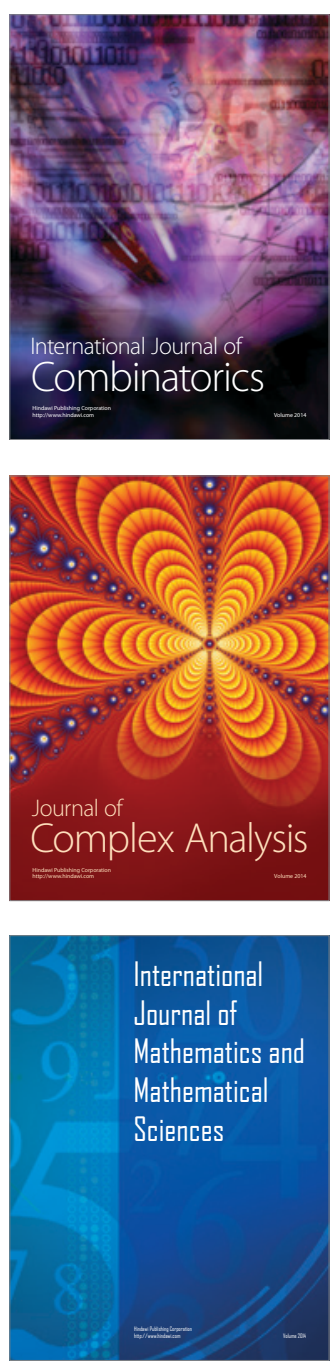
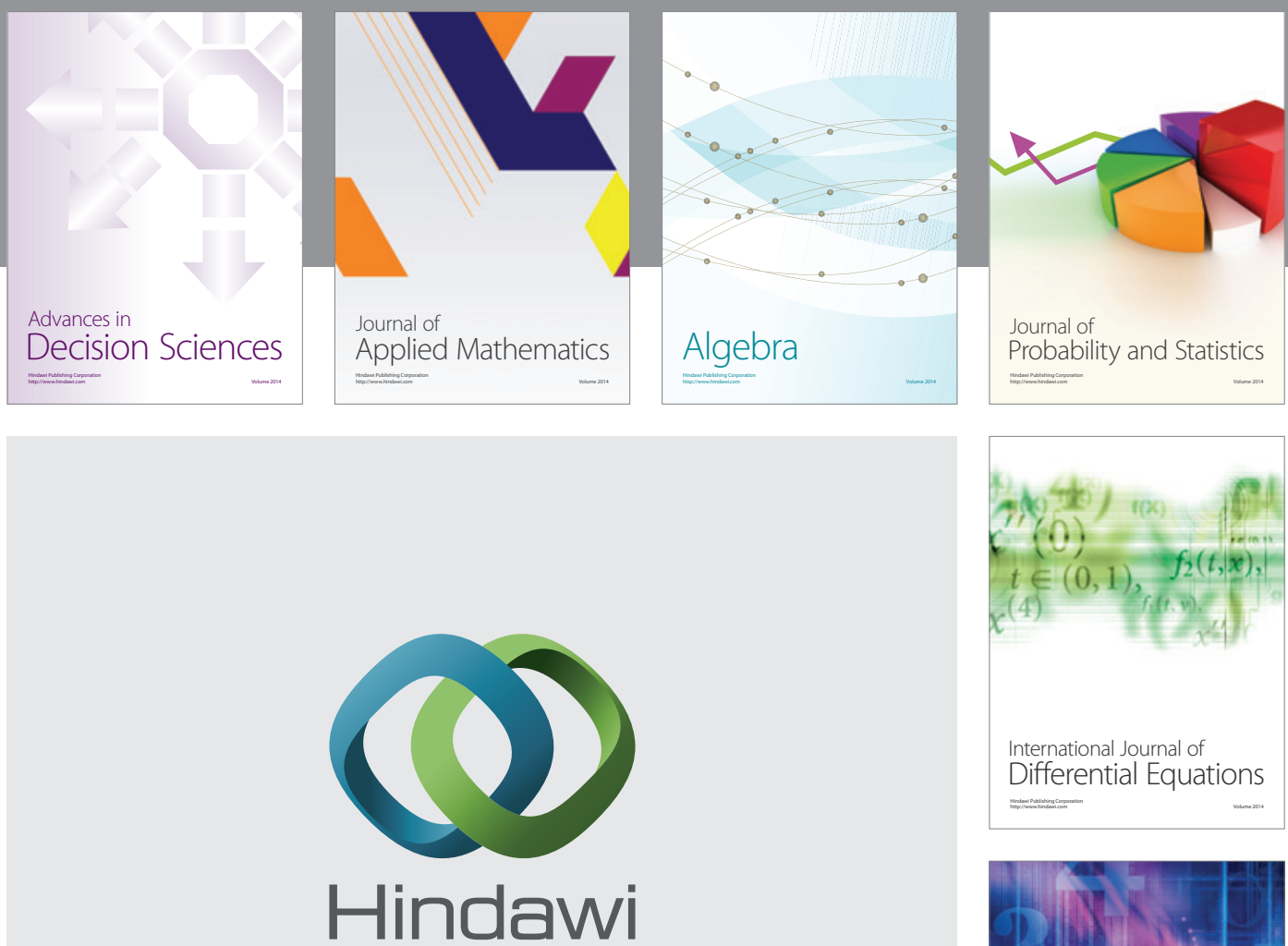

Submit your manuscripts at http://www.hindawi.com
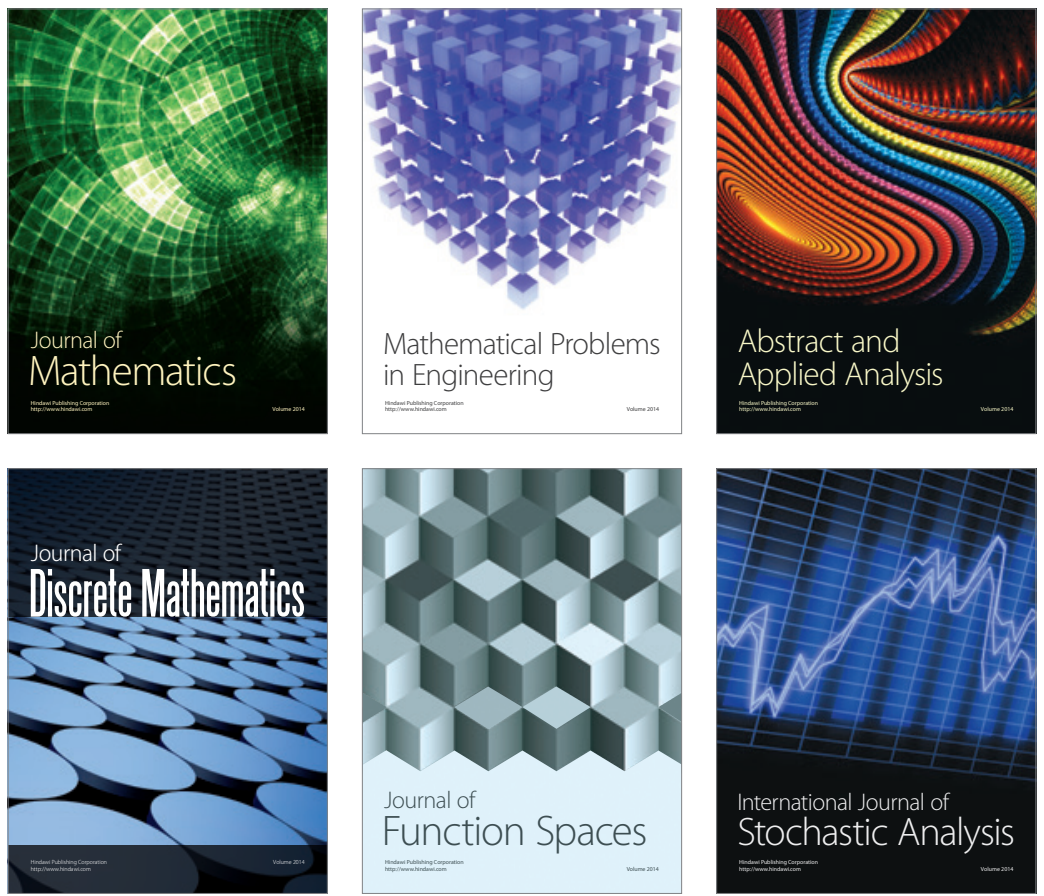

Journal of

Function Spaces

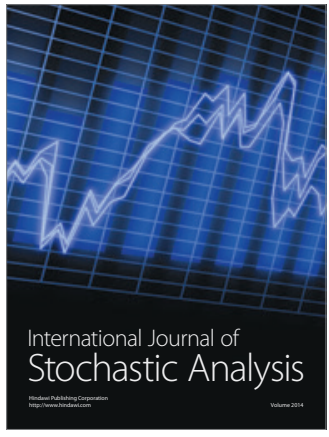

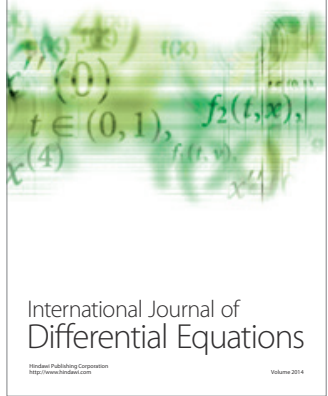
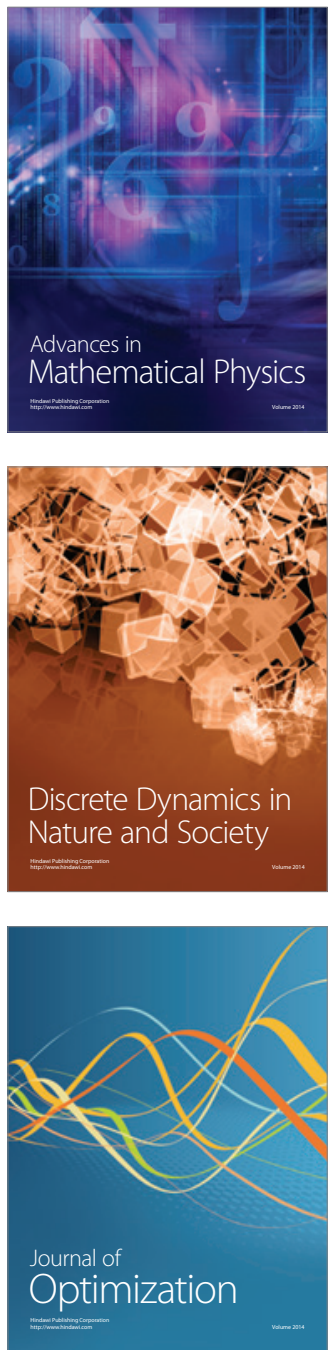